sonnel are among those who will also find the first section relevant.

Interest in this kind of book obviously appears mainly among those concerned with education and training, though industrial and government establishments may be included in this category as well as schools, universities and colleges. Although teachers will enjoy comparing the suggested courses with their own, the book should be regarded as a reference work, for there are detailed and careful sections on equipment, experimental procedure, and "evaluation and report", which make continuous reading heavy going. Also, in Britain, rigid adherence to these sections in a laboratory course is not very probable, as much of the apparatus and some of the materials used at Purdue are different from those generally at hand here. (Some of the references are also less accessible here. For example, United States Department of Commerce publications relating to health hazards and precautions may be less attractive than the "Introductory Manual on the Control of Health Hazards from Radio-active Materials", available from the Isotope Division at Harwell.) Teachers may also feel that these detailed experimental instructions leave too little to the student's imagination. On the other hand, the sections on the theoretical background which accompany each experiment lose little of their value in crossing the Atlantic. Apart from the variations in symbols and notation, which, as the authors say, are an inevitable feature of nuclear study at present, these sections would apply to almost all introductory laboratory courses in the techniques relating to radioactivity.

The experiments described in Part 1 would be generally accepted as suitable material for this kind of course. They include Geiger counter and ionization chamber techniques, but scintillation counting is relegated to the nuclear physics section, and the proportional counter has only scanty treatment. Some amplification of the neutron mean-life experiment would increase its value to engineers studying nuclear energy ; for example, indium foil activation enables the neutron distribution to be examined.

The remaining parts of the book describe experiments which are best regarded as further training in the techniques dealt with in Part 1 . The chemical and physical theory involved is not in itself up to honours degree standard, while there is no extensive investigation of possible applications of the techniques of radioactivity in research in either field. The references at the end of each chapter, which include publications up to 1951, do enable more elaborate or comprehensive ideas to be followed up, however.

R. L. Fortescue

\section{APPLICATIONS OF ELECTRICITY IN HORTICULTURE}

\section{Electricity in the Garden}

By Geoffrey Gerard. Pp. $x+125+16$ plates. (London: W. H. and L. Collingridge, Ltd.; New York: Transatlantic Arts, Inc., 1953.) 15s. net.

7 HE Briton is an inveterate gardener. In few countries can there be a greater proportion of keen amateurs, assiduously cultivating their home plots, often under far-from-promising climatic and topographical conditions. It is good that this should be so. We needed all the home-grown food that could be produced during the War and, if shortages are now less acute, there is still profit-and much pleasure - to be gained from gardening as a hobby. As electricity has become a great benefactor in the home, so it can be also in the garden. Electrically operated appliances for the garden are not really new but, in spite of their continued development during the past two or three decades, and the publicity which has been given to them from time to time in gardening journals and at horticultural shows, they are not as widely appreciated as they should be. Mr. Geoffrey Gerard's book is thus opportune. It should be very useful to the knowledgeable gardener in providing him with information on the best methods of using electrical equipment. which he may already possess, or may acquire, as well as giving, for the benefit of the uninitiated, a comprehensive account of the possibilities. But the book is not confined to matters of interest only to the amateur ; electrical methods for soil warming in frames and glasshouses, space heating and artificial illumination certainly concern the professional grower, and many of the illustrations are taken from commercial practice.

There are, of course, several important factors, varying widely in natural conditions, which affect the growth of plants-light, air temperature and humidity, soil temperature and moisture content, and the carbon dioxide content of the air as well as the chemical, bacteriological and mechanical conditions in the soil or other growing medium. In spite of research extending over many years, we are still far from knowing exactly what relative values of these quantities are required to bring about optimum growth at different stages of the development of plants; but plant physiologists such, for example, as Dr. F. W. Went, of California Institute of Technology, seem to be approaching the point where they can give a 'recipe' for growing some of the more important horticultural crops. If they succeed in doing so there is little doubt that electrical methods of controlling these factors precisely can be found. The problem for the commercial grower will then be to decide how far he can afford to go in applying these methods in his practical operations. Mr. Gerard's book does not attempt to instruct the grower in such economic matters but, at least, the author has taken pains to present the results of up-to-date research and development. $\mathrm{He}$ has drawn freely on the Electrical Research Association's reports upon its electro-horticultural researches at the Shinfield Field Station, and has given full references to these and other publications which can provide the interested reader with more detailed information.

It is good to note also the care which has been taken to point out the dangers of bad workmanship in installing the necessary electrical equipment. The chapters giving some instruction on the elements of electrical engineering and on maintenance of the installation are appropriate and are clearly written, and there is also an appendix giving the Draft British Standard Code of Practice for Farm and Horticultural Electrical Installations.

The book is well produced, and both the photographic and line-drawing illustrations are particularly good. If one feels that its price is rather high, that may be due to the difficulty in growing accustomed to the present-day costs of producing a book of this kind. $\quad$ E. W. GoLDING 